insanity described as abulic ( $\dot{\alpha}, \beta$ ov $\lambda \dot{\eta}-$ will) in whic $h$ violence and vehemence are more often due to loss than to increase of will-power, and in which there occars as a clinical symptom a distinct loss of control of the higher inhibitory centres over thought and action. Moreover, there is an etiology common to the insane and the victims of these fears ; in both there is a taint, both are among the neurotics, their relatives are the neurasthenic and the degenerate, although there may be of their kindred some who are noted for high literary and intellectual attainments. As to the pathology of impellent ideas the presumption that irregular stimulation of isolated cortical centres should cause motor instability on the one hand and vertiginous feelings, disturbed sensations, and emotions-corresponding to the subjective aspect-on the other, would seem to be as favourable a hypothesis as can be advanced according to our present knowledge.

Claybury.

\section{URTICARIA AND ACUTE CIRCUMSCRIBED CUTANEOUS CEDEMA.}

BY H. OPPENHEIMER, M.D. HEIDEL., M.R.C.P. LOND,

THE intimate relation existing between urticaria and that peculiar angio-neurosis known as "acute circumscribed cutaneous cedema" has been a matter of conjecture ever since Quincke first described the latter disease. It has been frequently observed that the same causes which in some individuals call forth a nettle-rash produce in others a peculiar flying cdema which, like the former, is frequently attended with gastro.intestinal disturbance. The connexion between these conditions can be easily understood if it be remembered that the pomphi of urticaria are themselves characterised by local oedematons exudations due to vasomotor influence; but in so far as I know, no cases are on record where both conditions co-existed at the same time in the same individual. Yet I do not think they can be very rare, as in less than three months I had four cases under my care where both urticaria and acute cutaneous odema were present in a well-marked form-unless, indeed, chance has played me that trick which has so frequently been a matter of surprise and has been honoured with the title, "the law of multiplicity of cases." Indeed, I am convinced that both disturbances are absolutely identical, varying only in their manifestations and in the external appearances with the intensity of the process, with the part of the body involved, and with the depth to which the skin is affected. And as I think that the following cases offer some peculiarities in other respects I consider it worth while to publish them.

CASE 1.-A man, aged twenty-five years, came to me on Nov. 20th, 1897, suffering from gonorrhcea. He had been taking sandal-wood oil for the last three days. On getting up on the morning of the 20th he felt an unbearable irritation of the skin, and on inspection he discovered large, well-marked pomphi on the chest, abdomen, and thighs, while the prepnce was enormously swollen. When I saw him in the middle of the day the eruption had spread to the back and arms, the tongue was furred, and I learned that the bowels had not acted for the last two days. I ordered him to discontinue the sandal-wood oil capsules, to take frequent tepid baths, and I gave him a mixture containing bicarbonate of sodium and carbonate of magnesium. In the evening he called again; the rash had reached the face and the eyelids were greatly swollen. I prescribed lead lotion for the eyelids and penis, and the next day the eruption had somewhat subsided. He made a gradual recovery which was complete in about a week.

CASE 2.-This patient was a man, aged thirty-two years, who had been previously under my care for chronic dyspepsia. He came to me on Jan. 4th, 1898. He had had for luncheon on the previous day venison which was rather "high." In the night he awoke with violent itching and noticed some red spots on his abdomen and thighs, while the upper eyelids were very much swollen. The treatment prescribed was as follows: tepid baths, a fall dose of Carlsbad salts, and bicarbonate of potassium in peppermint water. On the 5 th the upper eyelids were free but the lower ones were mucb $s$ wollen; the lips were enlarged to about four times their normal size and the hands were greatly swollen and showed livid discolouration. There were plenty of confluent wheals on the back, buttocks, the extensor surface of the arms and the posterior surface of the legs; a very few isolated ones were on the chest, abdomen, and flexor surface of the arms and anterior surface of the legs. There was no rash on the face. Lead lotion was prescribed. On the 6 th the eyelids were better. There was a plentiful eruption on the face and scanty spots were present on the scalp. The prepuce was very cdematous. On the limbs the order of things was reversed, those parts which previously were comparatively free being much affected anci vice versâ. Salicylate of sodium was given internally while lead lotion was applied to the penis and ichthyol ointment. to the hands. On the $7 \mathrm{th}$ the eruption was even more plentiful than on the day previous. There were enormous masses of wheals on the chest and abdomen. The face was better. The swelling of the hands and prepuce had almost disappeared, but the feet were so much swollen that the patient was unable to put on his slippers. Three grains of calomel and full doses of hydrochloric acid were given. On the 10 th the skin was perfectly free, but there was marked dermography. On the 13 th the patient bad a relapse after partaking freely of roast goose. The eyelids, lips, and feet were very œdematous. There was a free urticaria eruption on the chest and abdomen. On the 17th the slin was normal. There was no dermography.

CAS 3.-A man, aged twenty-three years, came to me on Jan. 17th, 1898. He suffered from cystitis and had been on an exclusive milk diet for the last three days and had taken salicylate of sodium on the 16th. He awoke next morning: with some pains in the wrist and ankles which were very much swollen and livid. The patient thought that he had acute rheumatism. For the last few hours he had felt very troublesome itching and on inspection I discovered a wellmarked nettle-rash which the patient had not noticed before. The bowels were freely open and the tongue was covered with a thick milk fur. I ordered him to stop the galicylate mixture, to take tepid baths, and prescribed lead lotion for external use and internally hydrochloric acid in full doses. On the 18 th the rash was fading away; there were no new eruptions. The ankles and wrists had decreased in size but the prepuce was very much swollen. On the 266 th the skin. had been normal for the last three days; the patient resumed the salicylate of sodiam, and on the very next day the rash reappeared even more plentifully than before. The trunk and limbs were almost completely covered with urticaria there were isolated pomphi on the face and scalp. The eyelids, lips, and prepuce showed cedematous infiltration. The previous treatment was resumed. On Feb. 1st the skin was perfectly normal and no more salicylate having been taken it has remained so.

CASE 4.-The patient was a woman, aged twenty-eight years, whom I saw on Jan. 21st, 1898. She had been previously healthy except for habitual constipation. On the 19th she had partaken of mussels and she awoke next night with a fearful initation of the skin, and on getting up in the morning discovered that her whole body except the face was covered with an eruption which proved to be urticaria and that the eyelids, hands, and feet were very much swollen. The bowels had not acted for the last three days; the tongue was clean. The eyelids were very pale and the hands and feet were dark livid. Warm baths, lead lotion for the eyelids, and ichthyol ointment for the hands and feet were preseribed and internally Carlsbad salts and hydrochloric acid. Or the 23rd the bowels bad not yet acted. The rash had somewhat decreased but had spread to the face and scalp. The eyelids and hands were free but the feet were still swollen and livid. The nymphæ were odematous and transformed into bags of the size of a hen's egg. The front and sides of the neck were blown up with serous transudation, so that the neck had the appearance of being surrounded by a thick collar. Calomel (two doses of three grains each) and hydro. chloric acid continued in increased doses were prescribed. On the 24th there was less irritation. The rash was still visible. The swellings were diminishing in size. One dose of calomel (two grains) was prescribed. On the 27 th the nettle-rash disappeared but the neck and feet were still somewhat enlarged. On Feb. 3rd the skin was perfectly normal.

Adamson-road, N.W. 